Article

\title{
Evolution of Carbon Shadow Prices in China's Industrial Sector during 2003-2017: A By-Production Approach
}

\author{
Wenyin Cheng ${ }^{1,+}$, Zhusong Yang ${ }^{1,+}{ }^{,}$Xia Pan ${ }^{2}$, Tomas Baležentis ${ }^{3}\left[\right.$ and Xueli Chen ${ }^{4,5, *}$ \\ 1 School of Public Policy and Management, Tsinghua University, Beijing 100084, China; \\ chengwy16@mails.tsinghua.edu.cn (W.C.); zhusong@tsinghua.edu.cn (Z.Y.) \\ 2 School of Statistics and Mathematics, Central University of Finance and Economics, Beijing 100081, China; \\ 2014311406@email.cufe.edu.cn \\ 3 Division of Farm and Enterprise Economics, Lithuanian Institute of Agrarian Economics, 03220 Vilnius, \\ Lithuania; tomas@laei.lt \\ 4 School of Languages and Media, Anhui University of Finance and Economics, 962 Caoshan Road, \\ Bengbu 233030, China \\ 5 Institute of Journalism and Communication, Chinese Academy of Social Sciences, Beijing 100732, China \\ * Correspondence: chenxl@cass.org.cn \\ + Cheng W. and Yang Z. share the first co-authorship.
}

Received: 6 January 2020; Accepted: 16 January 2020; Published: 19 January 2020

check for updates

\begin{abstract}
Global warming and the rapid growth of carbon emissions have attracted the attention of governments and academia throughout the world. In 2006, China surpassed the United States as the emitter of the greatest volume of carbon, the largest contribution of which is derived from China's industrial sector. This study investigated the evolution of industrial carbon shadow prices (CSPs) in China at the provincial level to assess the opportunity costs in terms of value added foregone owing to decreasing carbon emissions. A dual formulation of the by-production data envelopment analysis (DEA) model was applied to estimate the industrial carbon abatement costs in China during 2003-2017. This study represents the first attempt to apply the dual by-production DEA model for this purpose. Empirical results showed that industrial CSP increased by $3.83 \%$ annually and that the average provincial CSP was approximately $\$ 562.43 \mathrm{USD} /$ ton. A significant upturn in the CSP occurred after 2006. Furthermore, disparities of changes in industrial CSP over time were checked using the test of sigma convergence. Regional divergence was observed for the period 2011-2017. Policy implications were derived from the empirical results in terms of improvements regarding carbon abatement.
\end{abstract}

Keywords: Chinese industry; carbon shadow price; by-production technology; environmental performance; carbon abatement cost

\section{Introduction}

China became the world's largest emitter of carbon in 2006 and its greatest consumer of energy in 2011. Data from the BP Statistical Review of World Energy [1] shows that carbon dioxide $\left(\mathrm{CO}_{2}\right)$ emissions and energy consumption in China in 2018 reached 9428.70 million tons and 3273.50 million tons oil equivalent, accounting for $27.82 \%$ and $23.61 \%$ of the world's total, respectively. The industrial sector is the major contributor to economic growth in China; however, it is also responsible for producing the largest volume of carbon emissions and consuming the greatest quantity of energy [2]. According to estimates by Chen [3], the industrial sector contributed $83.1 \%$ of total carbon emissions and accounted for $67.9 \%$ of total energy consumption in China during 1980-2006.

China has promised to reduce carbon intensity (carbon emissions per unit gross domestic product, GDP) by $40-45 \%$ until 2020 and by 60-65\% until 2030 using 2005 as the base year. Carbon emissions in 
China are projected to peak at around 2030. In fact, China has already taken a variety of measures to reduce its $\mathrm{CO}_{2}$ emissions, and the 2020 goal was actually realized in 2017 when carbon intensity fell by $46 \%$. The 11th Five-Year Plan (2006-2010) for China was the first to set binding environmental goals represented by indicators. This allowed stricter control with regard to implementation of strategic measures. The development of quantitative and institutional frameworks for the promotion of sustainable economies has been discussed by Song et al. [4,5], Popov et al. [6], and Raszkowski and Bartniczak [7].

Carbon trading is one of the most effective market-based measures for the mitigation of carbon emissions. $\mathrm{CO}_{2}$ emission is a typical externality, which is supposed to be curbed by the introduction of property rights $[8,9]$. A carbon emission allowance is a type of property right that is allocated initially to certain firms, which other firms are then allowed to purchase. The economic losses from carbon abatement are likely to vary considerably among firms. Carbon trading allows the same level of marginal abatement costs to be reached within the market. In October 2011, China started pilot carbon trading schemes in seven provinces and cities, including four province-level municipalities-i.e., Beijing, Tianjin, Shanghai, and Chongqing-and Hubei (Wuhan), Guangdong (Guangzhou), and Shenzhen. Subsequently, the central government of China initiated the establishment of a National Carbon Trading Market. The World Bank and the United Nations have both predicted that China will surpass the European Union to become the world's largest carbon market by 2020 [10].

Without a functioning market, the prices of undesirable outputs are unavailable. For example, carbon emission is a typical undesirable output, yet its price must be estimated because it is not available on the market in many instances. Estimation of the carbon shadow price (CSP) is critical for making rational decisions regarding carbon trading. Several previous studies investigated the shadow price of pollutants in China. For example, Yuan et al. [11] measured the CSP of China's industrial sector in 2004 and 2008 using the nonparametric directional distance function (DDF) and found that the price varied in the range of $\$ 30-17,190 \mathrm{USD} / \mathrm{ton}$. Xie et al. [12] estimated the $\mathrm{SO}_{2}$ shadow price of China's industrial sector during 1998-2011 using the parametric quadratic DDF and found an upward trend. Tang et al. [13] estimated the shadow prices of pollutants in China's agricultural sector using a parameterized quadratic output DDF. They found an upsurge of the shadow price of total nitrogen, but fluctuating trends for the shadow prices of chemical oxygen demand and total phosphorus during 2001-2010. Estimation of a quadratic output DDF by Che [14] resulted in an upward trajectory for CSP of China's iron and steel industry during 2006-2012. Zeng et al. [15] estimated China's $\mathrm{SO}_{2}$ shadow price using an output DDF and found that the average shadow price of China's $\mathrm{SO}_{2}$ emissions decreased during 2001-2012. However, none of the above studies examined the evolution of the CSP with regard to the Chinese industrial sector using the by-production approach.

This study investigated the evolution of the CSP of China's industrial sector across 30 provinces during 2003-2017. The research focused on the following two hypotheses: the CSP has increased in China owing to improved environmental regulations, and the CSP across the provinces of China has converged. The novel by-production approach (especially, its dual formulation) was applied in the analysis. Compared with existing studies that calculated the CSP assuming weak disposability of good and bad outputs, this study represented the first application of by-production technology based on its dual formulation, which satisfied the materials balance requirement among other desiderata. Therefore, the derived policy implications are based on reasonable estimates.

The remainder of this paper is organized as follows. Section 2 reviews the estimation of the CSP in the earlier literature. Section 3 presents the by-production model. Section 4 discusses the data used in the study and the empirical analysis. Conclusions are provided in Section 5.

\section{Review of Estimation Methods for Carbon Shadow Price}

Pittman [16] incorporated pollution into productivity measurements and estimated the associated marginal abatement costs. Thereafter, other methods based on distance functions were proposed for estimating shadow prices without complete information on the market prices of inputs and outputs. 
Based on the dual function of revenue, cost, and profit functions, three streams of approach can be followed to estimate the shadow price of pollution using a distance function. Färe et al. [17] suggested using the dual function of the revenue function, i.e., the translog Shephard output distance function, to calculate the shadow price. Turner [18] computed shadow prices by combining data envelopment analysis (DEA) with the subvector Shephard output distance function. Hailu and Veeman [19] utilized the dual function of the cost function, i.e., the translog Shephard input distance function, within a deterministic parametric approach to estimate the shadow price of undesirable outputs.

Reports on the use of the DDF for estimation of shadow prices and environmental performance have increased in number. Compared with approaches based on the input distance function or the output distance function, the approach based on the DDF is able to distinguish between desirable and undesirable outputs in a realistic way. For instance, it can accommodate the way in which decision-making units (DMUs) are willing to optimize their activities, e.g., by expanding production and contracting pollution. Färe et al. [20] measured the shadow prices of undesirable outputs by exploiting the dual function of the profit function, i.e., the DDF. In addition, Färe et al. [21] also derived the shadow price of undesirable outputs using a quadratic DDF. Murty et al. [22] estimated the shadow price of pollutants from India's coal-fired thermal power plants using the DDF. Rødseth [23] constructed a novel DDF model by considering various abatement choices, e.g., emission control, pollution permits, and substitution between inputs and outputs. Song et al. [24] proposed a novel DDF model based on an output-oriented slacks-based measure.

A large body of literature has emphasized the importance of considering externalities in the form of undesirable outputs [24-27]. Unlike the free disposability assumption in models that take undesirable outputs as inputs or as desirable outputs, conventional DDF models [28-31] account for the negative externality of pollution by assuming weak disposability of desirable and undesirable outputs. Nevertheless, weak disposability technology violates the physical laws of mass-energy conservation [32-34].

To overcome the above problem, the by-production model was proposed recently by Murty and Russell [32] and Murty et al. [35]. This model divides technology into two independent components: the intended-production sub-technology and the residual-generating sub-technology. Although the latter (involving undesirable outputs) is assumed to follow costly disposability, the sub-technology relating to inputs and desirable outputs still follows the axiom of free disposability. Shen et al. [36] were the first to apply the by-production model to the case of China when studying the economic and environmental performances of China's agricultural sector. Shen et al. [36] considered national aggregate values as the direction of optimization in their by-production model, whereas we adopted province-level data as the direction of optimization, which was necessary for the calculation of the CSPs. Moreover, we used the dual formulation of the by-production model, which provided an unbiased estimate for deriving policy implications.

\section{Methodology}

The CSP denotes the amount of revenue that a DMU has to forego to reduce carbon emissions by a single unit. This measure is useful in providing economic assessment of environmental regulations when implementing carbon mitigation policies. Strategies for estimation of shadow prices can be categorized in two main groups, i.e., parametric and nonparametric approaches. The first group involves predefined functional forms of representations of production technology (e.g., the Cobb-Douglas, translog, or quadratic functional forms). This study adopted the nonparametric approach, which relies on linear programming and does not require a predefined functional form for representation of production technology. In our case, the DEA was applied as an estimator. In this section, we begin with the basic definitions of environmental production technology. 


\subsection{Environmental Production Technology}

Murty and Russell [32] and Murty et al. [35] argued that traditional approaches for modeling undesirable outputs (e.g., the weak disposability model) might lead to unacceptable economic implications. Therefore, they introduced the by-production technology to model environmental production possibilities. Suppose there are $K$ provinces in China, and that each province can be regarded as a DMU with associated quantities of inputs and outputs. Two groups of inputs can be defined in the environmental production technology, i.e., clean inputs $\left(x^{n}\right)$ and dirty inputs $\left(x^{p}\right)$. Both types of input can produce desirable outputs $(y)$, while only dirty inputs generate undesirable outputs $(z)$. Note that clean inputs do not contribute to the generation of $z$, whereas the opposite holds for dirty inputs. For instance, here, labor force and capital stock are clean inputs and energy consumption is a dirty input. Production technology is separated into two sub-technologies: the production process that focuses on intended outputs is termed the first sub-technology $\left(T_{1}\right)$. In our empirical application, the value added of the industrial sector is generated by exploiting the labor force, capital stock, and energy. The pollution-generating process is modeled in the second sub-technology $\left(T_{2}\right)$. Here, the provincial carbon emissions generated by energy consumption are used to measure industrial environmental performance. The by-production technology $\left(T_{B P}\right)$ proposed by Murty et al. [35] can be defined as follows:

$$
\begin{aligned}
T_{B P} & =T_{1} \cap T_{2} \\
& =\left\{\left(x^{n}, x^{p}, y, z\right) \in R_{+}^{N+P+M+J}:\left(x^{n}, x^{p}\right) \text { can produce } y ; x^{p} \text { can generate } z\right\} ; \\
T_{1} & =\left\{\left(x^{n}, x^{p}, y\right) \in R_{+}^{N+P+M} \mid f\left(x^{n}, x^{p}, y\right) \leq 0\right\} ; \\
T_{2} & =\left\{\left(x^{p}, z\right) \in R_{+}^{P+J} \mid g\left(x^{p}\right) \leq z\right\},
\end{aligned}
$$

where $f$ and $g$ are continuously differentiable functions with existing derivatives with respect to inputs and outputs, respectively. Murty et al. [35] and Shen et al. [36] both highlighted that the sub-technologies satisfy certain economic assumptions, e.g., convexity, closedness, disposability, and returns to scale. To distinguish desirable and undesirable outputs, free disposability $\left(A_{1}\right)$ is imposed on $T_{1}$ for all inputs and desirable outputs. The latter property implies that the given output quantities can be produced using more inputs than necessary, or that the given quantities of inputs can produce less output. The costly disposability $\left(A_{2}\right)$ is imposed on $T_{2}$ for pollution-generating inputs and undesirable outputs, which indicates that undesirable outputs cannot be abandoned freely as is the case for desirable outputs. The free disposability and cost disposability axioms are formally given as follows:

$$
\begin{aligned}
& A_{1}: \text { if }\left(x^{n}, x^{p}, y, z\right) \in T_{1} \text {, then }\left(\widetilde{x}^{n}, \widetilde{x}^{p}, \widetilde{y}, \widetilde{z}\right) \in T_{1} \text { for all }\left(-\widetilde{x}^{n},-\widetilde{x}^{p}, \widetilde{y}\right) \leq\left(-x^{n},-x^{p}, y\right) \text {. } \\
& A_{2}: \text { if }\left(x^{p}, z\right) \in T_{2} \text {, then }\left(\widetilde{x}^{p}, \widetilde{z}\right) \in T_{2} \text { for all }\left(\widetilde{x}^{p},-\widetilde{z}\right) \leq\left(x^{p}, z\right) \text {. }
\end{aligned}
$$

\subsection{Output-Oriented Directional Distance Function}

To evaluate the CSP of the industrial sector across the Chinese provinces, a measure of environmental efficiency based on by-production technology is introduced to evaluate the DMUs. The distance function is an equivalent representation of production possibility sets and it is a tool used commonly for measuring the improvement space from the evaluated DMUs (provinces) to the production frontier. Based on the improved output-oriented Färe-Grosskopf-Lovell index introduced by Murty et al. [35], Shen et al. [36] proposed a nonradial measurement of DDF that allows for the linearity of by-production technology. Here, we employ an output-oriented distance function that is able to increase desirable outputs and decrease undesirable outputs simultaneously. This DDF is defined as follows:

$$
D\left(x, y, z ; g_{x}, g_{y}, g_{z}\right)=\max \left\{\delta, \theta \in R_{+}:\left(x, y+\delta g_{y}, z-\theta g_{z}\right) \in T_{B P}\right\},
$$


where $\delta$ and $\theta$ can be interpreted as the inefficiency scores that denote the maximum possible increase in desirable outputs and decrease in undesirable outputs, respectively. If $\delta=0$ or $\theta=0$, the evaluated province serves as a benchmark regarding a certain sub-technology. Based on Equation (3), the DDF can be evaluated by solving the following linear program:

$$
\begin{aligned}
& D\left(x, y, z ; 0, g_{y^{\prime}}, g_{z}\right)=\max _{\delta, \theta, \lambda, \sigma} \frac{1}{2}\left(\sum_{m=1}^{M} \delta^{m} / M+\sum_{j=1}^{J} \theta^{j} / J\right) \\
& \text { s.t. } \sum_{k=1}^{K} \lambda_{k} y_{k}^{m} \geq y_{k^{\prime}}^{m}+\delta^{m} g_{y}^{m}, m=1, \cdots, M, \\
& \sum_{k=1}^{K} \lambda_{k} x_{k}^{n} \leq x_{k^{\prime}}^{n}, n=1, \cdots, N, \\
& \sum_{k=1}^{K} \lambda_{k} x_{k}^{p} \leq x_{k^{\prime}}^{p} p=1, \cdots, P, \\
& \sum_{k=1}^{K} \lambda_{k}=1, \\
& \lambda_{k} \geq 0, k=1, \ldots, K, \\
& \sum_{k=1}^{K} \sigma_{k} z_{k}^{j} \leq z_{k^{\prime}}^{j}-\theta^{j} g_{z}^{j}, j=1, \cdots, J, \\
& \sum_{k=1}^{K} \sigma_{k} x_{k}^{p} \geq x_{k^{\prime}}^{p} p=1, \cdots, P, \\
& \sum_{k=1}^{K} \sigma_{k}=1, \\
& \sigma_{k} \geq 0, k=1, \ldots, K,
\end{aligned}
$$

where the nonzero directional vector $\left(0, g_{y}, g_{z}\right)$, which is defined as the observed output quantities, implies that the province seeks to maximize desirable outputs and minimize undesirable outputs. Here, $\lambda_{k}$ and $\sigma_{k}$ are activity variables for $T_{1}$ and $T_{2}$ that suggest that two production frontiers are allowed with different benchmarks. The assumption of variable returns to scale related to $T_{1}$ and $T_{2}$ is represented by the constraints of $\sum_{k \in K} \lambda=1$ and $\sum_{k \in K} \sigma=1$, respectively.

Each linear program has its own corresponding dual formulation. The dual model allows for derivation of the shadow prices of desirable outputs $\left(\pi_{y}\right)$ in $T_{1}$ and those of undesirable outputs $\left(\omega_{z}\right)$ in $T_{2}$. The dual formulation of the linear program in Equation (4) was developed by Baležentis et al. [37], and it takes the following form:

$$
\begin{aligned}
& \begin{array}{ll}
D\left(x, y, z ; 0, g_{y}, g_{z}\right)= & \min _{\pi_{y}, \pi_{x}^{n}, \pi_{x}^{p}, \omega_{x}^{p}, \omega_{z,}, v_{1}, v_{2}}\left[\left(\sum_{n=1}^{N} \pi_{x}^{n} x_{k^{\prime}}^{n}+\sum_{p=1}^{P} \pi_{x}^{p} x_{k^{\prime}}^{p}\right.\right. \\
& \left.\left.\quad-\sum_{m=1}^{M} \pi_{y}^{m} y_{k^{\prime}}^{m}-v_{1}\right)+\left(\sum_{j=1}^{J} \omega_{z}^{j} z_{k^{\prime}}^{j}-\sum_{p=1}^{P} \omega_{x}^{p} x_{k^{\prime}}^{p}+v_{2}\right)\right] \\
\text { s.t. } \sum_{m=1}^{M} \pi_{y}^{m} y_{k}^{m}-\sum_{n=1}^{N} \pi_{x}^{n} x_{k}^{n}-\sum_{p=1}^{P} \pi_{x}^{p} x_{k}^{p}+v_{1} \leq 0, k=1, \ldots, K, & \\
& \sum_{p=1}^{P} \omega_{x}^{p} x_{k}^{p}-\sum_{j=1}^{J} \omega_{z}^{j} z_{k}^{j}-v_{2} \leq 0, k=1, \ldots, K, \\
& \sum_{m=1}^{M} \pi_{y}^{m} g_{y}^{m}=0.5 / M, \\
& \sum_{j=1}^{J} \omega_{z}^{j} g_{z}^{j}=0.5 / J, \\
& \pi_{y}^{m} \geq 0, m=1, \ldots, M, \\
& \pi_{x}^{n} \geq 0, n=1, \ldots, N, \\
& \pi_{x}^{p} \geq 0, p=1, \ldots, P, \\
& \omega_{x}^{p} \geq 0, p=1, \ldots, P, \\
& \omega_{z}^{j} \geq 0, j=1, \ldots, J,
\end{array}
\end{aligned}
$$


where $\pi_{x}^{n}, \pi_{x}^{p}$, and $\pi_{y}$ are the shadow values associated with the clean inputs, dirty inputs, and desirable outputs, respectively, in sub-technology $T_{1} ; \omega_{x}^{p}$ and $\omega_{z}$ are the shadow values of the dirty inputs and undesirable outputs, respectively, generated as defined by sub-technology $T_{2} ;$ and variables $v_{1}$ and $v_{2}$ represent the variable returns to scale assumption in $T_{1}$ and $T_{2}$, respectively. The objective function in Equation (5) seeks the minimum shadow profit by summing the observed shadow profits across the two sub-technologies.

The CSP can be derived as a ratio of the shadow values from Equation (5). The resulting CSP indicates the opportunity costs associated with decreasing the undesirable outputs by a single additional unit and thus abandoning the desirable outputs. Shen et al. [36] argued that the CSP could be considered the marginal abatement cost for each DMU. The case of energy-related carbon emissions can be considered as an example. As carbon emissions are produced by consumption of energy, carbon emissions are linked to the underlying emission factors. Thus, reduction in carbon emissions requires decline in energy consumption following the material balance condition. Finally, the desirable outputs (including the value added) will be contracted owing to decline in the input quantity (energy consumption). Thus, the CSP is obtained as follows:

$$
C S P=\frac{\omega_{z}^{j}}{\pi_{y}^{m}}=-\frac{\partial \hat{D}\left(x, y, z ; 0, g_{y}, g_{z}\right) / \partial z}{\partial \hat{D}\left(x, y, z ; 0, g_{y}, g_{z}\right) / \partial y} .
$$

The levels and trends of the CSP could represent valuable information for policy makers. A higher CSP indicates greater marginal carbon abatement cost, i.e., a DMU would have to cede further desirable output for a given level of carbon reduction, and vice versa. If there were two DMUs, A and B, and the value of the CSP for A were greater than that for B, then policy makers might persuade $B$ to curb its carbon emissions to a greater extent. Boussemart et al. [25] highlighted that rich provinces in China have a high CSP, while less-developed regions show relatively low abatement costs. Moreover, the evolution of the CSP implies improving environmental performance if the CSP is rising. Knowledge of such change could help policy makers evaluate conditions regarding the abatement activities of the DMUs.

\section{Data and Results}

\subsection{Data}

This study focused on industrial production, including mining and quarrying, manufacturing, electricity, heat, gas, and water. The period of investigation was 2003-2017. Labor was measured based on the number of employees of firms in the industrial sector. The data were obtained from the China Statistical Yearbook for Regional Economy [38], statistical yearbooks of each province, China Economic Census database [39], and EPS database [39]. Capital refers to the capital stock employed in the industry, which was calculated using the perpetual inventory method. The data on fixed asset investment were taken from the National Bureau of Statistics [40]. The variation in depreciation rate among different provinces was taken into account with reference to the depreciation rate of each province given in Jiang et al. [41].

Energy consumption represents the final energy consumption by the industrial sector. It is equal to the total energy consumption, excluding the consumption for conversion of primary energy into final energy and losses during energy transformation. The data, derived from the China Energy Statistics Yearbook [42], covered 22 types of energy in terms of physical units. We converted the data to the unit of coal equivalent based on standard conversion factors. It is noteworthy that data on five types of energy (i.e., liquefied petroleum gas, liquefied natural gas, blast furnace gas, converter gas, and coal gangue) were missing for 2003-2009. The value added represents the desirable output of the industrial sector. The data were taken from the National Bureau of Statistics [40]. The emission factors for the various energy types were collected from the Intergovernmental Panel on Climate Change [43] and the 
National Development and Reform Commission [44]. Data for the province of Tibet were not available. All monetary variables were deflated by price indices obtained from the National Bureau of Statistics website [40] using constant prices of 2011 as benchmarks. Descriptive statistics of the five variables are shown in Table 1. The total number of observations was 450.

Table 1. Descriptive statistics of variables defining production technology.

\begin{tabular}{llllll}
\hline Variable & Units & Mean & Std.Dev & Min & Max \\
\hline Labor & millions & 3.94 & 4.10 & 0.14 & 19.77 \\
Capital & billions US dollars & 249.81 & 290.51 & 3.25 & 1847.53 \\
Energy & million tons of standard coal & 53.83 & 39.84 & 0.784 & 195.25 \\
Value added & billions US dollars & 9.93 & 96.33 & 2.16 & 530.19 \\
$\mathrm{CO}_{2}$ & million tons & 166.87 & 124.00 & 5.44 & 569.38 \\
\hline
\end{tabular}

Note: in 2011, 1 US dollar was approximately equal to 7 yuan.

\subsection{Empirical Results}

As listed in Table 2, the values of industrial CSP for the Chinese provinces followed an increasing trend (average rate of growth: $3.83 \%$ p.a.), and the average CSP was approximately $\$ 562.43 \mathrm{USD} /$ ton during the entire period of study. Figure 1 shows that the trend of industrial CSP in China could be divided into three subperiods. The first stage covers 2003-2007 when the CSP decreased from $\$ 534.14$ $\mathrm{USD} /$ ton to $\$ 439.71 \mathrm{USD} / \mathrm{ton}$. It shows that the model of economic growth in China was generally extensive before the 2008 financial crisis. The second stage refers to the period 2007-2016 when the CSP maintained rapid increase. This can be attributed to the binding goals represented by specific environmental indicators set by central government in the Five-Year plans since 2006. The third stage is represented by slight decline of the CSP after 2016. On signing up to the Paris Agreement in 2016, China promised to start building its National Carbon Trading Market in 2017. The expectations associated with the establishment of the National Carbon Trading Market could explain the temporary decrease of the CSP at this time. However, various reasons could have contributed to the slowing of the progress of this plan scheduled for the first half of 2017. Although the plan was not released officially until the end of 2017, to a certain extent, it might have affected the emission reduction behaviors of provinces and departments, which could have caused the decline of the CSP at national and regional levels.

The provincial and regional evolutions of industrial CSP are shown in Table 2 and Figure 1. The eastern region exhibited the highest CSP in China, and most provinces had a positive trend. The only exception is Hainan Province, which had a slightly negative trend, which might reflect the rapid development of its energy-intensive industries after 2007. Indeed, certain energy-consuming industries (e.g., the petroleum processing industry, natural gas chemical industry, and power industry) have been identified as the pillar industries of Hainan Province. These industries contributed $54.4 \%$ of the total industrial output value in 2007 [45].

Guangdong Province had the highest CSP, and the actual carbon emissions in Guangdong were close to the goal set by the government [46]. Furthermore, as the most developed city in Guangdong, Shenzhen faces serious environmental constraints [47]. Ningxia had the lowest CSP, which might reflect its relative technical inefficiency [48].

Two inland provinces showed decline of the CSP-Heilongjiang and Xinjiang. Being the old industrial bases in China, the three northeastern provinces (i.e., Heilongjiang, Liaoning, and Jilin) all had low CSPs. However, the energy structure of Heilongjiang Province is dominated by coal [49], which is likely the reason for its lower absolute value and downward trend of its CSP. In addition, a mode of extensive development prevails in Heilongjiang Province, which implies substantial energy consumption, high levels of pollution, and low efficiency [50]. Zhang et al. [51] highlighted that the unreasonable industrial structure in Xinjiang Province is an important reason for the increase of regional carbon emissions. Actually, the value added of several energy-intensive sectors (e.g., petroleum processing, the chemical industry, and oil and gas extraction) accounts for a large share of the provincial 
GDP in Xinjiang. However, these sectors feature low energy efficiency and they contribute $90 \%$ (almost all) of the direct (indirect) carbon emissions in Xinjiang.

Generally, most economically developed provinces are located in the eastern region of China, and the results indicate that these provinces face increasing carbon abatement costs. In comparison with the eastern area, the industrial CSP of provinces in inland and western regions is lower. However, the lower level of the CSP in inland and western regions suggests that their environmental production technology might be less efficient and/or they tend to consume more energy inputs. This result is consistent with the findings in Boussemart et al. [25], Zhou et al. [52], and Song et al. [5].

Table 2. Description of the carbon shadow price (CSP) of the Chinese industrial sector (USD/ton).

\begin{tabular}{|c|c|c|c|c|c|c|}
\hline Region & Province & Mean & $\operatorname{Max}$ & Min & Std.Dev. & Trend (\%) \\
\hline \multirow{12}{*}{ Eastern } & Beijing & 712 & 1300 & 361 & 306 & 9.40 \\
\hline & Fujian & 869 & 1409 & 576 & 275 & 5.60 \\
\hline & Guangdong & 1095 & 1529 & 678 & 283 & 5.87 \\
\hline & Guangxi & 586 & 855 & 425 & 139 & 4.76 \\
\hline & Hainan & 353 & 397 & 313 & 25 & -0.01 \\
\hline & Hebei & 354 & 433 & 283 & 45 & 2.68 \\
\hline & Jiangsu & 793 & 1074 & 499 & 167 & 4.78 \\
\hline & Liaoning & 425 & 551 & 314 & 89 & 1.53 \\
\hline & Shandong & 601 & 810 & 426 & 123 & 4.40 \\
\hline & Shanghai & 766 & 1019 & 544 & 138 & 4.01 \\
\hline & Tianjin & 802 & 1255 & 405 & 284 & 8.12 \\
\hline & Zhejiang & 914 & 1293 & 695 & 206 & 4.63 \\
\hline \multirow{9}{*}{ Inland } & Anhui & 510 & 714 & 350 & 136 & 5.50 \\
\hline & Heilongjiang & 704 & 1841 & 306 & 487 & -11.19 \\
\hline & Henan & 640 & 894 & 479 & 134 & 3.10 \\
\hline & Hubei & 564 & 964 & 327 & 231 & 8.60 \\
\hline & Hunan & 620 & 940 & 356 & 232 & 8.39 \\
\hline & $\begin{array}{l}\text { Inner } \\
\text { Mongo. }\end{array}$ & 267 & 459 & 178 & 67 & -0.20 \\
\hline & Jiangxi & 737 & 904 & 561 & 121 & 3.00 \\
\hline & Jilin & 442 & 696 & 202 & 179 & 9.71 \\
\hline & Shanxi & 283 & 340 & 233 & 31 & 0.79 \\
\hline \multirow{9}{*}{ Western } & Chongqing & 647 & 1017 & 401 & 215 & 7.27 \\
\hline & Gansu & 313 & 358 & 275 & 26 & 1.38 \\
\hline & Guizhou & 214 & 375 & 122 & 92 & 8.94 \\
\hline & Ningxia & 166 & 214 & 134 & 22 & -0.25 \\
\hline & Qinghai & 405 & 547 & 221 & 113 & 5.46 \\
\hline & Shaanxi & 696 & 1675 & 461 & 299 & -0.32 \\
\hline & Sichuan & 723 & 964 & 500 & 176 & 3.57 \\
\hline & Xinjiang & 300 & 367 & 217 & 59 & -4.31 \\
\hline & Yunnan & 369 & 603 & 236 & 135 & 7.27 \\
\hline China & Average & 562 & 1841 & 122 & 294 & 3.83 \\
\hline
\end{tabular}

Note: trend indicates stochastic annual growth rates for 2003-2017 as estimated using the ordinary least squares method. The unit of the CSP is USD/ton and in 2011, one US dollar was approximately equal to seven yuan. 


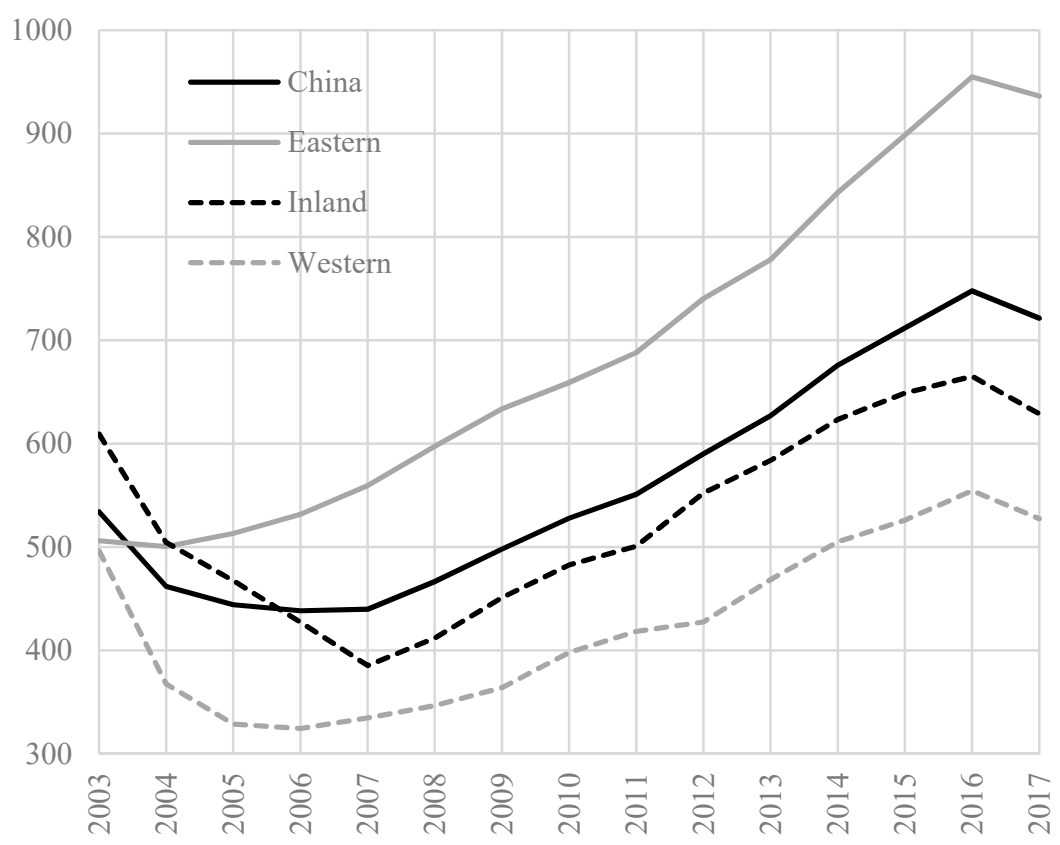

Figure 1. Average CSP of the Chinese industrial sector during 2003-2017 (USD/ton).

Kernel densities can be used to reveal the complex distributions of economic variables. The distribution of industrial CSP across the three main regions of China is depicted in Figure 2. The range of the CSP is $\$ 121.71-1840.71$ USD/ton. The CSP is centered on $\$ 400$ USD/ton in most provinces. However, disparities in the distributions of the CSP can be observed, i.e., they are clearly all right-skewed distributions.

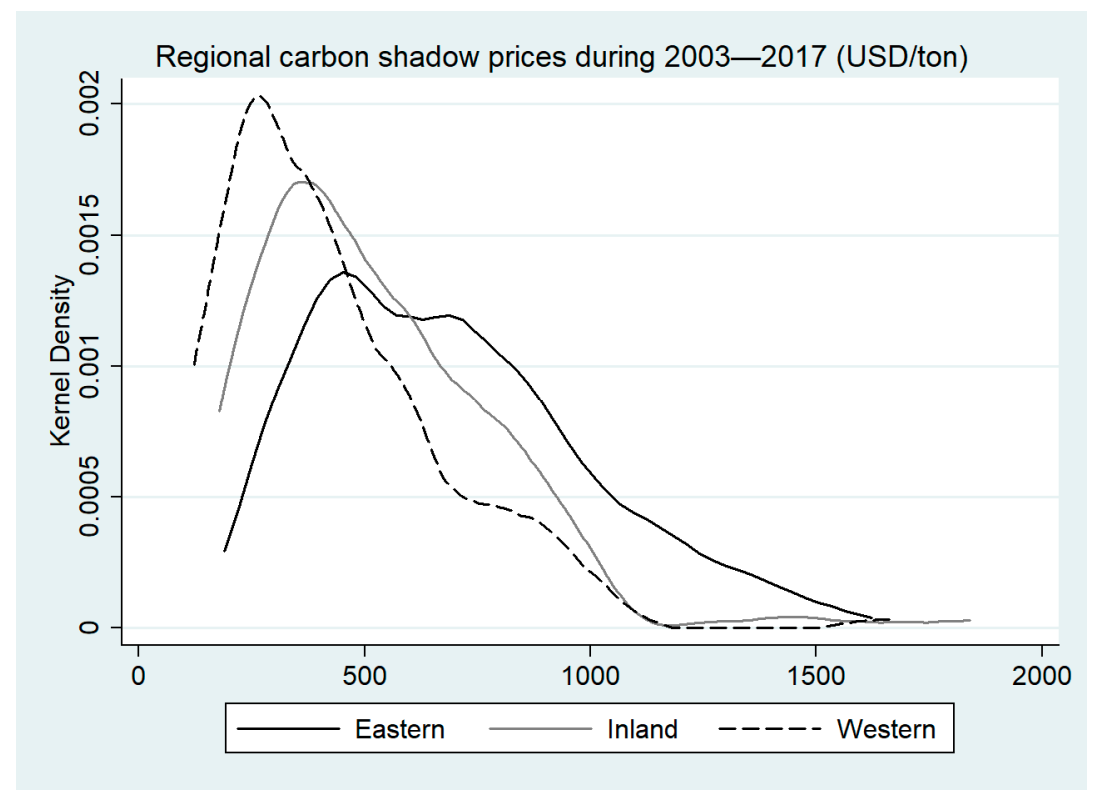

Figure 2. Kernel density plots of the CSP across the three main regions of China.

To identify the changes in industrial CSP over time, time-specific distributions are depicted for each region in Figures 3-5. In the eastern region (Figure 3), it can be seen that the kernel density is displaced to the right, which corresponds to growth in the industrial CSP. Moreover, the curve is flattening, which confirms the increasing disparity of the CSP among the provinces. It implies regional imbalance, especially in terms of environmental governance, which was also found by both 
Chen et al. [53] and Jin et al. [54]. Different patterns of the dynamics in the distributions of the CSP can be observed in inland (Figure 4) and western (Figure 5) regions. Instead of maintaining growth, the industrial CSP shows a type of sigma convergence in these regions during 2003-2010.

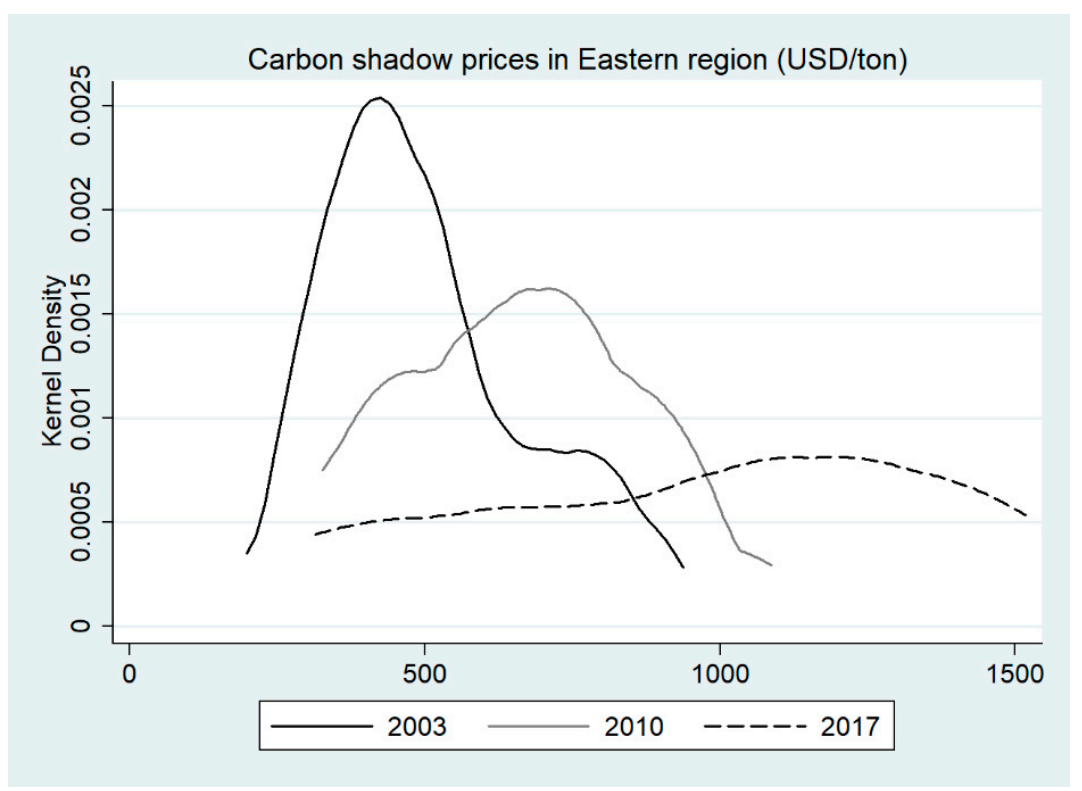

Figure 3. Kernel density plot of the CSP in the eastern region of China.

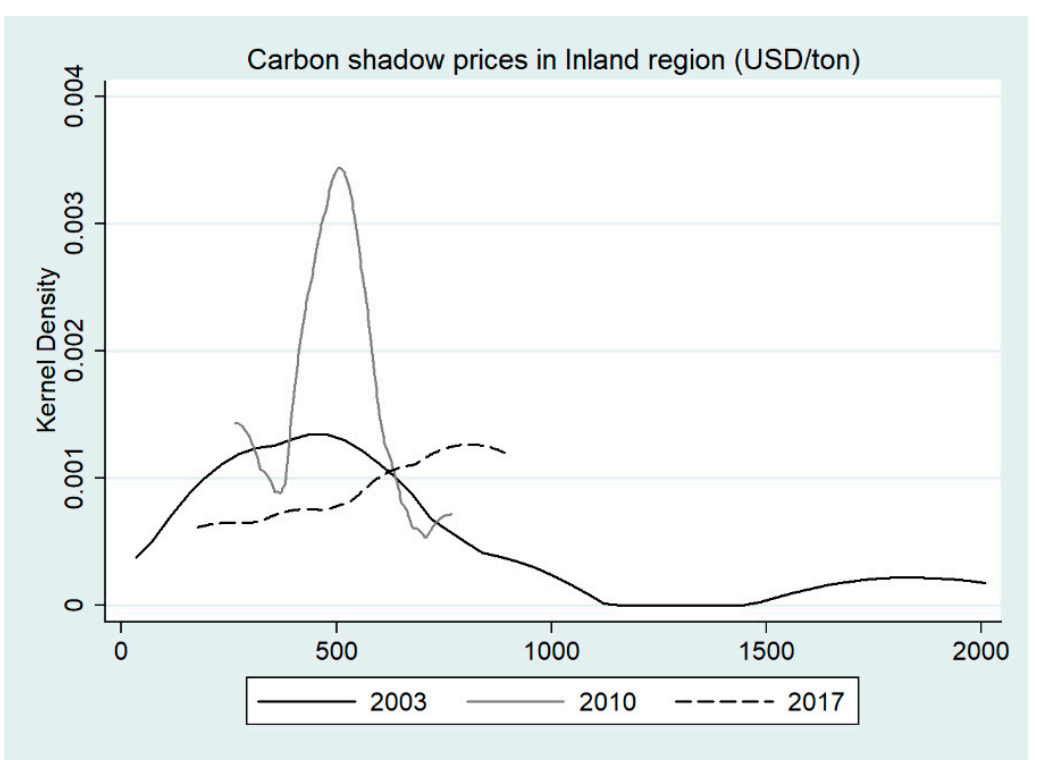

Figure 4. Kernel density plot of the CSP in the inland region of China. 


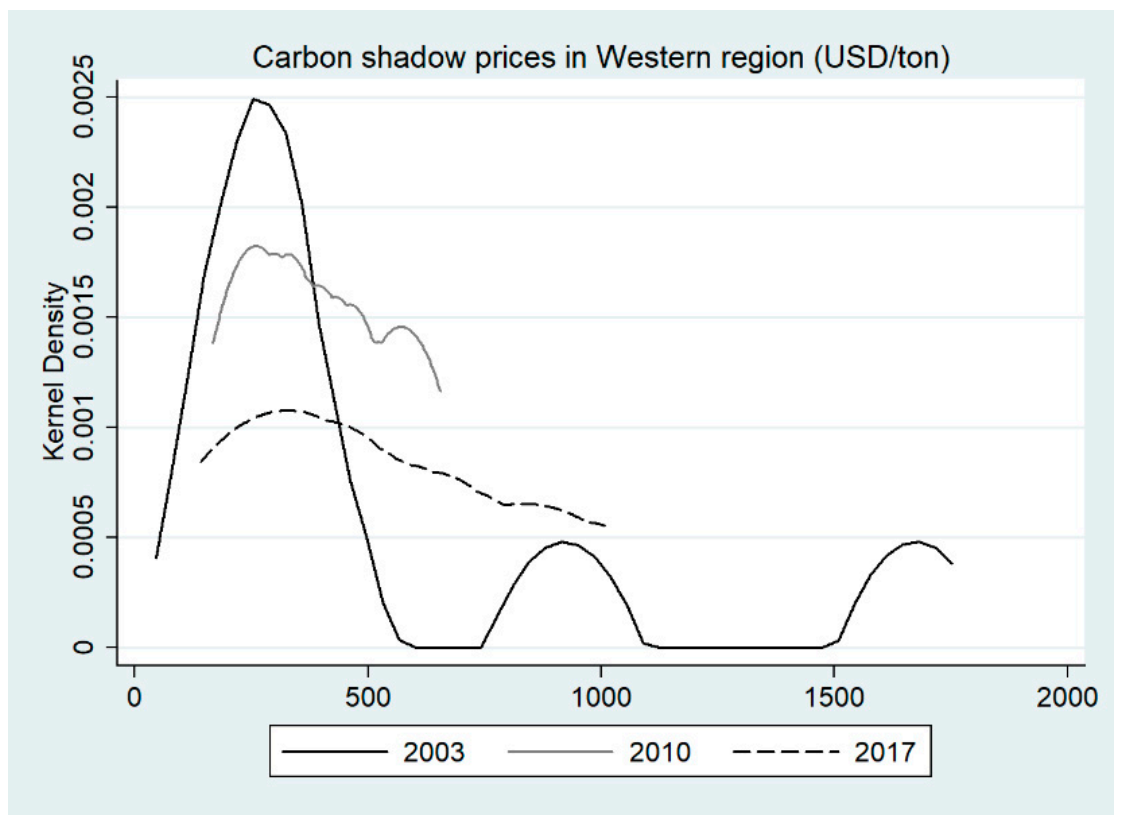

Figure 5. Kernel density plot of the CSP in the western region of China.

The sigma convergence was tested for the three regions of China by regressing the coefficient of variation on the trend over time. As shown in Table 3, the coefficient of variation of the industrial CSP on the trend over time was negative in both inland ( -0.59 p.a.) and western $(-0.48$ p.a.) areas in the first period. However, divergence in the CSP occurred during 2011-2017. For instance, the positive trend (0.39 p.a.) in the inland region was statistically significant $(t$-value $=4.46)$, indicating increasing disparity. These results are in agreement with those of both Boussemart et al. [25] and Zhou et al. [52].

Table 3. Tests of sigma convergence of industrial CSP among the three main regions of China.

\begin{tabular}{ccccc}
\hline Period & 2003-2010 & \multicolumn{2}{c}{ 2011-2017 } \\
\hline & Trend Coefficient & $\boldsymbol{t}$-Value & Trend Coefficient & $\boldsymbol{t}$-Value \\
\hline Eastern & 0.06 & 2.85 & 0.37 & 7.68 \\
Inland & -0.59 & -5.37 & 0.39 & 4.46 \\
Western & -0.48 & -3.18 & 0.13 & 1.53 \\
\hline
\end{tabular}

Note: the linear trend was estimated by considering the coefficient of variation as the dependent variable and the time index as the independent variable.

\section{Conclusions}

This study investigated the cost of carbon emission abatement in China's industrial sector during 2003-2017. A nonparametric framework based on by-production technology was employed to estimate provincial-and regional-level CSPs. For this purpose, a dual formulation of the by-production DEA model was developed and applied, which to the best of our knowledge represented this first such a model has been applied to CSP evaluation. The sigma convergence test was applied to examine the evolution of marginal abatement costs across the three main regions of China.

Generally, the results showed an increase of the CSP in the Chinese industrial sector, which implies increasing costs associated with further reduction in carbon emissions. With regard to the convergence of regional CSPs, inland and western regions of China showed significant convergence during 2003-2010 but divergence throughout the rest of 2001-2017, whereas divergence was observed in the eastern region during the entire study period. The following policy implications can be derived based on the empirical results. First, environmental performance should be defined in terms of binding goals set by the government to ensure efficient policy implementation. Indeed, the binding goals 
represented by the environmental indicators set by central government in the Five-Year plans since 2006 resulted in obvious upturn of the CSP. Second, the National Carbon Trading Market should be developed further to alleviate the severe regional imbalance in carbon emissions across China. In fact, the Ministry of Ecology and Environment of China has been making great efforts to build a National Carbon Trading Market since the end of 2017, following a six-year implementation of the pilot scheme for carbon trading. Third, stricter supervision of environmental pollution is needed for inland and western regions of China, especially those provinces with deteriorating carbon emission performance (e.g., Heilongjiang and Xinjiang). Within the eastern region, the spillover of cleaner production technologies is especially topical because of the increased spread in the CSP across the provinces. Information on CSPs might assist the government in setting up an effective carbon trading system and encourage funding for the promotion of cleaner technologies. Differences in the leverage effect of the money spent on existing environmental programs in China are evidenced by the increasing spread of the CSPs.

It is recognized that this study had certain limitations. For instance, the research focused on estimation of the industrial CSP without consideration of other economic sectors. Therefore, future research should compare the dynamics of the CSP across different sectors of the Chinese economy, which would allow deeper insight into the possible effects of carbon trading.

Author Contributions: Introduction and Review of estimation methods for carbon shadow price, W.C.; Methodology, X.C. and T.B.; Data and Results, W.C., X.P., and X.C.; Conclusions, W.C., Z.Y., and T.B.; Writing-Original Draft Preparation, W.C., Z.Y., X.P., and X.C.; Writing-Review and Editing, T.B. All authors have read and agreed to the published version of the manuscript.

Funding: This research was funded by the National Science Foundation of China key project grant number 71733003, the Special Funding for National Top Think Tanks by the National Office for Philosophy and Social Sciences of the Propaganda Department of the CPC Central Committee grant number 20155010298.

Conflicts of Interest: The authors declare no conflict of interest.

\section{References}

1. BP. Statistical Review of World Energy. 2019. Available online: https://www.bp.com/en/global/corporate/ energy-economics/statistical-review-of-world-energy.html (accessed on 20 November 2019).

2. Teng, X.; Liang, C.; Chiu, Y.H. Energy and emission reduction efficiency of China's industry sector: A non-radial directional distance function analysis. Carbon Manag. 2019, 10, 333-347. [CrossRef]

3. Chen, S.Y. Energy consumption, $\mathrm{CO}_{2}$ emission and sustainable development in Chinese industry. Econ. Res. J. 2009, 4, 41-55. (In Chinese)

4. Song, M.; Fisher, R.; Kwoh, Y. Technological challenges of green innovation and sustainable resource management with large scale data. Technol. Forecast. Soc. Chang. 2019, 144, 361-368. [CrossRef]

5. Song, M.; Zhu, S.; Wang, J.; Zhao, J. Share green growth: Regional evaluation of green output performance in China. Int. J. Prod. Econ. 2020, 219, 152-163. [CrossRef]

6. Popov, E.V.; Veretennikova, A.Y.; Kozinskaya, K.M. Formal Institutional Environment Influence on Social Entrepreneurship in Developed Countries. Montenegrin J. Econ. 2019, 14, 45-56. [CrossRef]

7. Raszkowski, A.; Bartniczak, B. Towards sustainable regional development: Economy, society, environment, good governance based on the example of Polish regions. Transform. Bus. Econ 2018, 17, $225-245$.

8. Coase, R.H. The Problem of Social Cost. J. Law Econ. 1960, 3, 1-44. [CrossRef]

9. Demsetz, H. Toward a Theory of Property Rights. Am. Econ. Rev. 1967, 57, 347-359.

10. Mao, X. Environomist: China Carbon Market Research Report 2017; Environomist Ltd.: Beijing, China, 2017.

11. Yuan, P.; Liang, W.; Cheng, S. The Margin Abatement Costs of $\mathrm{CO}_{2}$ in Chinese Industrial Sectors. In Proceedings of the 2nd International Conference on Advances in Energy Engineering (ICAEE), Bangkok, Thailand, 27-28 December 2011; Zeng, D., Ed.; Energy Procedia: Amsterdam, The Netherlands, 2012.

12. Xie, H.; Shen, M.; Wei, C. Technical efficiency, shadow price and substitutability of Chinese industrial $\mathrm{SO}_{2}$ emissions: A parametric approach. J. Clean. Prod. 2016, 112, 1386-1394. [CrossRef]

13. Tang, K.; Gong, C.; Wang, D. Reduction potential, shadow prices, and pollution costs of agricultural pollutants in China. Sci. Total Environ. 2016, 541, 42-50. [CrossRef] 
14. Che, L. Shadow Price Estimation of $\mathrm{CO}_{2}$ in China's Regional Iron and Steel Industry. In Proceedings of the 8th international conference on applied energy (ICAE2016), Beijing, China, 8-11 October 2016; Yan, J., Sun, F., Chou, S.K., Desideri, U., Li, H., Campana, P., Xiong, R., Eds.; Energy Procedia: Amsterdam, The Netherlands, 2017.

15. Zeng, S.; Jiang, X.; Su, B.; Nan, X. China's $\mathrm{SO}_{2}$, shadow prices and environmental technical efficiency at the province level. Int. Rev. Econ. Financ. 2018, 57, 86-102. [CrossRef]

16. Pittman, R.W. Multilateral productivity comparisons with undesirable outputs. Econ. J. 1983, 93, $883-891$. [CrossRef]

17. Färe, R.; Grosskopf, S.; Lovell, C.K.; Yaisawarng, S. Derivation of shadow prices for undesirable outputs: A distance function approach. Rev. Econ. Stat. 1993, 75, 374-380. [CrossRef]

18. Turner, J. Measuring the Cost of Pollution Abatement in the Electric Utility Industry: A Production Function Approach. Ph.D. Thesis, University of North Carolina, Chapel Hill, NC, USA, 1994.

19. Hailu, A.; Veeman, T.S. Environmentally Sensitive Productivity Analysis of the Canadian Pulp and Paper Industry, 1959-1994: An Input Distance Function Approach. J. Environ. Econ. Manag. 2000, 40, 251-274. [CrossRef]

20. Färe, R.; Grosskopf, S.; Weber, W.L. Shadow Prices of Missouri Public Conservation Land. Public Financ. Rev. 2001, 29, 444-460. [CrossRef]

21. Färe, R.; Grosskopf, S.; Noh, D.W.; Weber, W. Characteristics of a Polluting Technology: Theory and Practice. J. Econom. 2005, 126, 469-492. [CrossRef]

22. Murty, M.N.; Kumar, S.; Dhavala, K.K. Measuring Environmental Efficiency of Industry: A Case Study of Thermal Power Generation in India. Environ. Resour. Econ. 2007, 38, 31-50. [CrossRef]

23. Rødseth, K.L. Capturing the least costly way of reducing pollution: A shadow price approach. Ecol. Econ. 2013, 92, 16-24. [CrossRef]

24. Song, M.; Wang, S. DEA decomposition of China's environment efficiency based on search algorithm. Appl. Math. Comput. 2014, 247, 562-572.

25. Boussemart, J.P.; Leleu, H.; Shen, Z. Environmental growth convergence among Chinese regions. China Econ. Rev. 2015, 34, 1-18. [CrossRef]

26. Shen, Z.; Boussemart, J.P.; Leleu, H. Aggregate green productivity growth in OECD's countries. Int. J. Prod. Econ. 2017, 189, 30-39. [CrossRef]

27. Chen, J.; Gao, M.; Ma, K.; Song, M. Different effects of technological progress on China's carbon emissions based on sustainable development. Bus. Strategy Environ. 2019, 1-12. [CrossRef]

28. Färe, R.; Grosskopf, S.; Pasurka, C.A. Accounting for Air Pollution Emissions in Measures of State Manufacturing Productivity Growth. J. Reg. Sci. 2001, 41, 381-409. [CrossRef]

29. Boyd, G.A.; George, T.; Joseph, P. Plant level productivity, efficiency, and environmental performance of the container glass industry. Environ. Resour. Econ. 2002, 23, 29-43. [CrossRef]

30. Tu, Z.G. The coordination of industrial growth with environment and resource. Econ. Res. J. 2008, 2, 93-105. (In Chinese)

31. Wang, Q.; Cui, Q.; Zhou, D.Q.; Wang, S. Marginal abatement costs of carbon dioxide in China: A nonparametric analysis. In Proceedings of the International Conference on Energy, Environment and Development (ICEED), Kuala Lumpur, Malaysia, 8-9 December 2010; Zhang, W., Ed.; Energy Procedia: Amsterdam, The Netherlands, 2011.

32. Murty, S.; Russell, R.R. On Modeling Pollution Generating Technologies; Discussion Papers Series; Department of Economics, University of California: Riverside, CA, USA, 2002; pp. 1-18.

33. Coelli, T.; Lauwers, L.; Van Huylenbroeck, G. Environmental efficiency measurement and the materials balance condition. J. Prod. Anal. 2007, 28, 3-12. [CrossRef]

34. Rødseth, K.L. Environmental efficiency measurement and the materials balance condition reconsidered. Eur. J. Oper. Res. 2016, 250, 342-346. [CrossRef]

35. Murty, S.; Russell, R.R.; Levkoff, S.B. On modeling pollution-generating technologies. J. Environ. Econ. Manag. 2012, 64, 117-135. [CrossRef]

36. Shen, Z.; Balezentis, T.; Chen, X.; Valdmanis, V. Green growth and structural change in Chinese agricultural sector during 1997-2014. China Econ. Rev. 2018, 51, 83-96. [CrossRef]

37. Baležentis, T.; Blancard, S.; Shen, Z.; Štreimikienè, D. Analysis of environmental total factor productivity evolution in European agricultural sector. Decis. Sci. 2019, e12421. [CrossRef] 
38. National Bureau of Statistics of China. China Statistical Yearbook for Regional Economy; China Statistics Press: Beijing, China, 1996-2018.

39. China Economic Census Database. EPS Database. Available online: http://olap.epsnet.com.cn/index.html (accessed on 20 November 2019).

40. National Bureau of Statistics in China. Available online: http://www.stats.gov.cn/ (accessed on 20 November 2019).

41. Jiang, Y.; Chen, X.; Valdmanis, V.; Baležentis, T. Evaluating Economic and Environmental Performance of the Chinese Industry Sector. Sustainability 2019, 11, 6804. [CrossRef]

42. National Bureau of Statistics of China. China Energy Statistical Yearbook; China Statistics Press: Beijing, China, 1996-2018.

43. Intergovernmental Panel on Climate Change. IPCC Guidelines for National Greenhouse Gas Inventories; Eggleston, H.S., Buendia, L., Miwa, K., Ngara, T., Tanabe, K., Eds.; Prepared by the National Greenhouse Gas Inventories Programme; IGES: Hayama, Japan, 2006.

44. National Development and Reform Commission. NDRC, PRC Guidelines for Provincial Greenhouse Gas Inventories; Prepared by the Climate Division, National Development and Reform Commission, PRC; NDRC: Beijing, China, 2011.

45. Pan, Q.; Xuan, L.; Zhang, Y. Analysis of the development of high energy-consuming industries in Hainan. Coop. Econ. Sci. 2008, 358, 15-16. (In Chinese)

46. Nie, W. Research on China's Carbon Trading Market Based on the Shadow Price of Carbon Emission. Master's Thesis, Jinan University, Guangzhou, China, 2018. (In Chinese).

47. Yi, L.; Li, Z.; Yang, L.; Liu, J.; Packianather, M. Evaluation on the development degree of China's seven pilot carbon markets. Chin. J. Popul. Resour. Environ. 2018, 16, 28-35. [CrossRef]

48. Chen, X.; Liu, Y. Estimation of China's carbon dioxide shadow price and analysis of the difference in transaction price: Output function based on quadratic directional distance. Ecol. Econ. 2018, 34, 14-20, 50. (In Chinese)

49. Liu, M.; Zhu, L.; Fan, Y. Evaluation of carbon emission performance and estimation of marginal $\mathrm{CO}_{2}$ abatement costs for provinces of China: A non-parametric distance function approach. China Soft Sci. 2011, 3, 106-114. (In Chinese)

50. Zhou, H.; He, S.; Xing, S. Regional industrial structure and heterogeneity of carbon dioxide shadow prices. J. Hunan Univ. Sci. Technol. 2018, 21, 69-77. (In Chinese)

51. Zhang, X.; Zhao, Y.; Wang, C. Sectorial difference on carbon emission of energy consumption in Xinjiang based on input-output principle. Resour. Ind. 2017, 19, 85-92. (In Chinese)

52. Zhou, X.; Fan, L.W.; Zhou, P. Marginal $\mathrm{CO}_{2}$ abatement costs: Findings from alternative shadow price estimates for Shanghai industrial sectors. Energy Policy 2015, 77, 109-117. [CrossRef]

53. Chen, J.; Xu, C.; Cui, L.; Huang, S.; Song, M. Driving factors of $\mathrm{CO}_{2}$ emissions and inequality characteristics in China: A combined decomposition approach. Energy Econ. 2019, 78, 589-597. [CrossRef]

54. Jin, P.; Peng, C.; Song, M. Macroeconomic uncertainty, high-level innovation, and urban green development performance in China. China Econ. Rev. 2019, 55, 1-18. [CrossRef]

(C) 2020 by the authors. Licensee MDPI, Basel, Switzerland. This article is an open access article distributed under the terms and conditions of the Creative Commons Attribution (CC BY) license (http://creativecommons.org/licenses/by/4.0/). 